\title{
Controlled Study of Mothers and Children in Hospital
}

\author{
D. J. BRAIN,* F.R.C.S. ; INGA MACLAY, $\dagger$ M.D., B.S., D.P.M.
}

Brit. med. F., 1968, 1, 278-280

In recent years increasing attention has been paid to the emotional problems which sometimes occur when children are admitted to hospital. Numerous papers have been written on the subject and there seem to be three general conclusions. Firstly, all children under 3 years of age and most of those under 5 are emotionally disturbed by admission to hospital. This is shown not only by their behaviour in the ward but also by their adverse reactions when they return home (Jessner and Kaplan, 1948 ; Robertson, 1952 ; Jackson et al., 1952, 1953 ; Schaffer and Callender, 1959). Secondly, though improved hospital conditions, better play and educational facilities, and greater awareness on the part of hospital staff of the emotional needs of children can lessen trauma for older children, the younger ones cannot be consoled for the loss of their mother by these means (Prugh et al., 1953; Illingworth and Holt, 1955 ; Vaughan, 1957 ; Plank et al., 1959). Thirdly, those workers who have published reports on mother and child units have been impressed by the beneficial effects of these on the child (Spence, 1946, 1947, 1951 ; MacCarthy, 1957; Craig and McKay, 1958 ; MacCarthy et al., 1962 ; Riley et al., 1965).

Though consistent agreement exists on these points, there has been a conspicuous lack of systematic study in this field. It was therefore decided to carry out a clinical trial in an effort to evaluate the claims which have been made for mother-andchild units.

\section{Material and Methods}

All the children in the trial were under 6 years of age and had been referred to one of us (D. J. B.) for tonsillectomy or adenoidectomy or both. The mothers of all the children (about 1,000) examined between June 1964 and December 1965 were asked whether they were willing to accompany their child into hospital for the operation if a bed was available for them. It was decided to limit the study to children whose mothers were willing to accompany them into hospital, as it was thought that the type of mother who agreed to this might be quite different from the type who was unable or unwilling to do so. No pressure was put on mothers to accept this offer and about $20 \%$ of those approached expressed willingness to come into hospital. Their children constituted both the experimental group whose mothers stayed with them in hospital and the control group who were admitted unaccompanied. Allocation to the two groups was made by the process of random selection. The same ward and staff (surgeon, anaesthetist, and nurses) were used for the two groups, who were admitted for a period of three days on alternate weeks. This prevented the children in the control group from feeling jealous at the sight of mothers accompanying the children in the other group. Parental visiting to children in the control group was limited.

The mothers of the children in the experiment were visited in their homes by one of us (I. M.) on three separate occasions. The first visit was made approximately one month before admission, and a full medical and social history of the child was taken. An assessment was also made of the emotional state of the mother, and the mother-child relationship, the marital

\footnotetext{
* Senior Clinical Tutor in Otorhinolaryngology, University of Birming-

ham.
$t$ Lecturer in Psychiatry, University of Birmingham.
}

adjustment of the parents, and the home background. The general practitioner concerned was also approached, and some useful information came from this source. A second domiciliary visit was made about two weeks after discharge from hospital, and was concerned with any change in the behaviour, habits, and physical health of the child since leaving hospital. A similar visit was also made about six months later. While the mothers and children were in hospital, observations were made on their behaviour by the two ward sisters (both of whom remained on the ward throughout the trial), and the anaesthetist (Dr. Martin) recorded the emotional reaction of each child during induction of anaesthesia.

\section{Results}

Of the 197 children admitted for tonsillectomy during the period of the survey 101 were allocated to the experimental group (admitted with mothers) and 96 to the control group (admitted alone).

There were no significant differences between the two groups with respect to any of the variables studied concerning their family and background-namely, age on admission to hospital, sex, parental ages at time of admission, social class, occupation of mother, number of siblings, birth rank, emotional state of child before admission to hospital, previous hospital admissions, marital adjustment of parents, emotional state of mother, mother-child relations, attitude of mother towards staying in hospital with her child, type of operation performed.

Adjustment of Children in Hospital.-Adjustment was defined as (a) satisfactory when the child indicated its awareness of the reality of the situation in which it found itself and was not unduly disturbed; (b) unsatisfactory when the child reacted to the hospital situation with panic or by complete denial and withdrawal ; and (c) limited when the child showed overt signs of emotional disturbance but was able to express its feelings to some extent and make a partial adjustment to the situation. There was a highly significant difference between the distribution of the two groups, the experimental group making a better adjustment to hospital (Table I).

\begin{tabular}{|c|c|c|c|c|c|c|c|}
\hline \multirow{2}{*}{\multicolumn{2}{|c|}{ Adjustment }} & \multicolumn{2}{|c|}{$\begin{array}{l}\text { Control } \\
\text { Group }\end{array}$} & \multicolumn{2}{|c|}{$\begin{array}{l}\text { Experimental } \\
\text { Group }\end{array}$} & \multicolumn{2}{|c|}{ Total } \\
\hline & & No. & $\%$ & No. & $\%$ & No. & $\%$ \\
\hline $\begin{array}{l}\text { Satisfactory } \\
\text { I.mited } \\
\text { Unsatisfactory... }\end{array}$ & $\begin{array}{l}\ldots \\
\cdots\end{array}$ & $\begin{array}{l}41 \\
42 \\
13\end{array}$ & $\begin{array}{l}42.7 \\
43.7 \\
13.6\end{array}$ & $\begin{array}{r}77 \\
21 \\
3\end{array}$ & $\begin{array}{r}76 \cdot 2 \\
20 \cdot 8 \\
3 \cdot 0\end{array}$ & $\begin{array}{r}118 \\
63 \\
16\end{array}$ & $\begin{array}{r}60.0 \\
31.9 \\
8.1\end{array}$ \\
\hline 'Total & ... & 96 & 100 & 101 & 100 & 197 & 100 \\
\hline
\end{tabular}

Emotional Disturbance after Discharge.-Children were classified (a) disturbed if any new behaviour disorder or neurotic trait had been observed since admission to hospital and (b) undisturbed if behaviour was unchanged. There was a highly significant difference between the two groups, the experimental group showing a lower incidence of emotional disturbance after discharge (Table II). There was a significant difference between the groups, emotional disturbance, when present, lasting for a shorter time in the experimental group (Table III). 
The individual types of disturbance reported by mothers after discharge were, in order of frequency: disturbed nights, clinging behaviour, aggression and/or temper tantrums, crying, irritability, spitefulness towards siblings, nocturnal enuresis, fear of hospitals, school refusal, encopresis, refusal to go outside, fear of death, babyish behaviour.

\begin{tabular}{|c|c|c|c|c|c|c|c|c|}
\hline \multirow{2}{*}{\multicolumn{3}{|c|}{ Emotional State }} & \multicolumn{2}{|c|}{$\begin{array}{l}\text { Control } \\
\text { Group }\end{array}$} & \multicolumn{2}{|c|}{$\begin{array}{l}\text { Experimental } \\
\text { Group }\end{array}$} & \multicolumn{2}{|c|}{ Total } \\
\hline & & & No. & $\%$ & No. & $\%$ & No. & $\%$ \\
\hline $\begin{array}{l}\text { isturbed } \\
\text { ndisturbed }\end{array}$ & $\because$. & $\because$. & $\begin{array}{l}53 \\
43\end{array}$ & $\begin{array}{l}55 \cdot 2 \\
44.8\end{array}$ & $\begin{array}{l}22 \\
79\end{array}$ & $\begin{array}{l}21.8 \\
78.2\end{array}$ & $\begin{array}{r}75 \\
122\end{array}$ & $\begin{array}{l}38.1 \\
61.9\end{array}$ \\
\hline Total & .. & .. & 96 & 100 & 101 & 100 & 197 & 100 \\
\hline
\end{tabular}

$x^{2}=23 \cdot 285$, d.f. $=21, \mathrm{P}<0.001$.

TABle III.-Duration of Emotional Disturbance After Discharge

\begin{tabular}{|c|c|c|c|c|c|c|}
\hline \multirow{2}{*}{ Duration } & \multicolumn{2}{|c|}{$\begin{array}{l}\text { Control } \\
\text { Group }\end{array}$} & \multicolumn{2}{|c|}{$\begin{array}{l}\text { Experimental } \\
\text { Group }\end{array}$} & \multicolumn{2}{|c|}{ Total } \\
\hline & No. & $\%$ & No. & $\%$ & No. & $\%$ \\
\hline Less than 2 weeks $\quad$. & 19 & $35 \cdot 8$ & 13 & $59 \cdot 1$ & 32 & $42 \cdot 7$ \\
\hline $\begin{array}{l}\text { months } \\
\text { Longer than } 6 \text { months }\end{array}$ & $\begin{array}{l}23 \\
11\end{array}$ & $\begin{array}{l}43.4 \\
20.8\end{array}$ & 9 & $\stackrel{40 \cdot 9}{0}$ & $\begin{array}{l}32 \\
11\end{array}$ & $\begin{array}{l}42 \cdot 7 \\
14 \cdot 6\end{array}$ \\
\hline Total & 53 & 100 & 22 & 100 & 75 & 100 \\
\hline
\end{tabular}

Postoperative Complications.-A postoperative complication was defined as a haemorrhage from the site of operation or an infection occurring within the first 10 postoperative days. There were four cases of haemorrhage and 29 postoperative infections. There was a significant difference between the two groups, $11 \%$ of the children in the experimental group having postoperative complications, compared with $23 \%$ in the control group.

Association Between Background Variables and Overall Disturbance due to Hospitalization.-The relation between emotional disturbance resulting from hospitalization and the background variables used in the comparison of the experimental and control groups was investigated. For this purpose children were regarded as " disturbed" if they had shown maladjustment either in hospital or after discharge, or on both occasions. Table IV shows the background variables significantly asso-

TABLE IV.-Association Between Background Variables and Overall

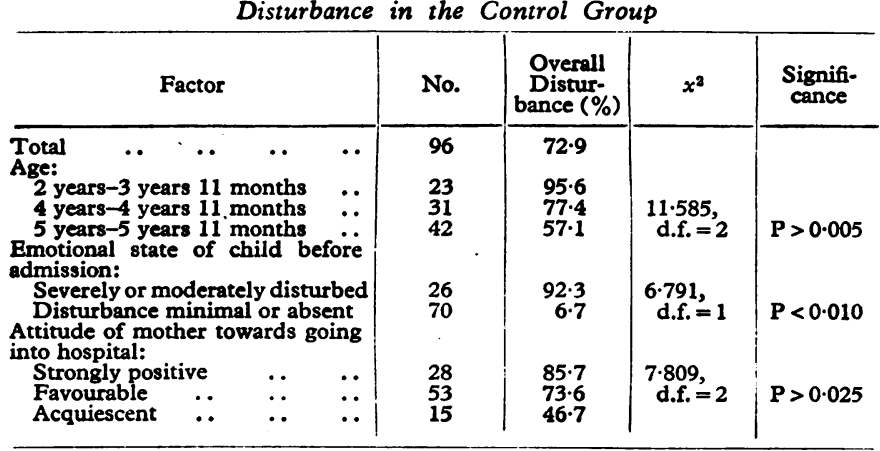

ciated with emotional disturbance in the control group. The incidence of disturbance due to hospitalization varied inversely with increasing age. Children who were emotionally maladjusted before admission were more likely to show further disturbance. The more anxious a mother was to accompany her child into hospital the more likely was the emotional disturbance if the child was admitted alone. In the experimental group only one background variable was significantly associated with disturbance due to hospitalization-namely, the emotional state before admission to hospital. Of those who were severely or moderately disturbed $58 \%$ were disturbed during admission, while when this factor was absent only $28 \%$ were disturbed.
Children who were emotionally maladjusted before admission were more likely to show further disturbance as a result of it.

TABLE V.-Attitude of 101 Mothers in Experimental Group Towards Going Into Hospital with Their Children Again

\begin{tabular}{|c|c|c|c|}
\hline Attitude of Mother & & No. & $\%$ \\
\hline $\begin{array}{l}\text { Would go into hospital again } \\
\text { Would not go into hospital again } \\
\text { Uncertain } . .\end{array}$ & \begin{tabular}{ll|}
. &. \\
$\because$ & $\because$.
\end{tabular} & $\begin{array}{r}86 \\
12 \\
3\end{array}$ & $\begin{array}{r}85.1 \\
11.9 \\
3.0\end{array}$ \\
\hline
\end{tabular}

TABLE VI.-Attitude of 96 Mothers in the Control Group Towards Their Children's Hospitalization

\begin{tabular}{|c|c|c|c|}
\hline Attitude of Mother & & No. & $\%$ \\
\hline $\begin{array}{ll}\text { Would like to have gone into hospital } & \\
\text { Glad she did not go into hospital } & \\
\text { Felt it would have made no difference } & \end{array}$ & $\because$ & $\begin{array}{l}37 \\
20 \\
39\end{array}$ & $\begin{array}{l}38.5 \\
20.8 \\
40 \cdot 6\end{array}$ \\
\hline
\end{tabular}

Attitudes of Nursing Staff.-Before the experiment began, the senior nursing sister on the ward expressed doubts regarding the advisability of admitting mothers with their children, but she and the rest of the staff were fully prepared to try the scheme and endeavoured to be open-minded. The staff were not specially selected for the experiment ; they were all trained and experienced, all but one were married and several had children of their own. At the end of the experiment they were unanimous in their opinion that they preferred the children to be admitted on their own, though they conceded that the mother's presence was often a great comfort to a very young child-a 2-year-old. The reasons given for not wanting the mothers were: $(a)$ it was easier to carry out nursing procedures when the child was alone, $(b)$ the nursing staff were able to make more personal contact with children admitted unaccompanied, and (c) a few of the mothers were "difficult" and upset both their own children and other mothers in the ward.

\section{Discussion}

There was a significant reduction in the incidence of emotional and infective complications when the child was accompanied by its mother. The overall incidence of postoperative infection (which occurred in 29 cases) was rather high, but some of these infections were acquired after leaving the ward. The reduced incidence of postoperative infection in the experimental group confirms the observations made by the Pickerills $(1945,1954)$. The nursing of children in cubicles by their mothers, thus minimizing contact with different members of ward staff, was probably the main factor in reducing infection.

The children of mothers who had a very strong desire to accompany their children into hospital but were unable to do so had a very high rate of emotional disturbance $(85.7 \%)$; whereas the incidence of disturbance was relatively low $(46.7 \%)$ when the attitude of the mother was more passive. This suggests that the mother is often the best judge of whether or not their children need them in hospital. Admission to hospital appeared to cause further distress to children already maladjusted, whether or not they were accompanied by their mothers.

About $85 \%$ of the mothers who were admitted with their children were satisfied with the arrangement and were prepared to repeat the experience. The nursing staff, however, preferred the children to be admitted on their own, and as the success of any medical unit depends largely on the attitudes of the staff the selection and training of nurses for work in mother-andchild units is extremely important and merits further investigation. The problem of "difficult" mothers is almost unavoidable, and it is an unfortunate fact that the staff will remember vividly one such mother while forgetting the many other cooperative ones. The staff at Rubery Hill Hospital felt strongly about mothers who upset the ward routine though only four out of the 98 mothers admitted had caused appreciable trouble. 
The mothers were quite unselected, and one of the nursing sisters felt that it would be a good idea to screen mothers before admission and omit the likely trouble-makers. In practice it would be difficult to do this without considerable knowledge of the mother and child ; furthermore, 22 out of the 27 mothers in the experimental group who were thought to be emotionally disturbed when the first home visit was made stayed in hospital with their children and caused no trouble whatsoever.

\section{Summary}

In this clinical trial 197 children were admitted to hospital for three days and underwent tonsillectomy and/or adenoidectomy. An experimental group of 101 were admitted with their mothers and there was a control group of 96 unaccompanied children. The incidence of emotional and infective complications was significantly lower in the experimental group.

This investigation was supported by a grant from the Birmingham Regional Hospital Board to one of us (D. J. B.), and much of this paper forms part of a thesis presented by I.M. for the degree of M.D. of London University. We wish to thank the Selly Oak Group Hospital Management Committee, Dr. J. R. Mathers and the nursing staff at Rubery Hill Hospital, and Dr. Sheila Martin for their invaluable help.

\section{REFERENCES}

Craig, J., and McKay, E. (1958). Brit. med. 7., 1, 275.

Illingworth, R. S. and Holt, K. S. (1955). Lancet, 2, 1257.

Jackson, K., Winkley, R., Faust, O. A., and Cermak, E. G. (1952). F Amer. med. Ass., 149, 1536.

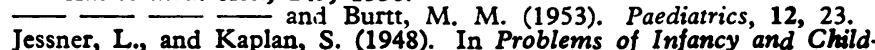
hood, edited by M. J. E. Senn. New York.

MacCarthy, D. (1957). Publ. Hlth, 71, 264

MacCarthy, Lind. H., and Morris, I. (1962). Lancet, 1, 603.

Pickerill, C. M., and Pickerill, H. P. (1954). ibid., 1, 425.

Pickerill, H. P., and Pickerill, C. M. (1945). Brit. med. f., $1,159$.

Plank, E. N., Caughey, P. A., and Lipson, M. J. (1959). Amer. \%. Orthopsychiat., 29, 94.

Prugh, D. G., Staub, E. N., Sands, H. H., Kirschbaum, R. M., and Lenihan, E. A. (1953). Ibid., 23, 70.

Riley, I. D., Syme, J., Hall, M. S., and Patrick, M. J. (1965). Brit. med. \%., 2, 990 .

Robertson, J. (1952). A Two-Year-Old Goes to Hospital (Film). London: Tavistock Clinic ; New York: University Film Library.

Schaffer, H. R., and Callender, W. M. (1959), Paediatrics, 24, 528.

Spence, J. C. (1946). The Purpose of the Family: A Guide to the Caro of Children. London.

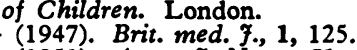
(1951). Amer. $¥$. Nurs., 51, 14.

Vaughan, G. F. (1957). Lancet, 1, 111.

\section{Treatment of Volvulus of Sigmoid Colon: a Review of 425 Cases*}

\section{J. J. SHEPHERD, $†$ M.D., F.R.C.S.ED.}

Brit. med. F., 1968, 1, 280-283

The treatment of volvulus of the sigmoid colon is a subject of controversy. With the dual objective of relieving obstruction and preventing recurrence, immediate laparotomy and resection of the redundant loop is recommended by Aylett (1954), Douglas (1956), Ahsan and Rahman (1967), and Rains and Capper (1965).

Hall-Craggs (1960) submitted that recurrence could be prevented by plication of the mesentery and fixation of the sigmoid loop, and Souttar (1956) thought that fixation was sometimes of value.

The development of a non-operative method of treatment by sigmoidoscopy and intubation was credited by Anderson (1956) to Schilling, of Oslo, and was described in detail by Bruusgaard (1947). The major objections to conservative management are as follows: (1) the deflated colon may be or may become gangrenous (Aylett, 1954; Hinshaw and Carter, 1957); (2) intubation may damage the oedematous bowel wall (Douglas, 1956); and (3) an opportunity of preventing recurrence is lost (Hall-Craggs, 1960 ; Ahsan and Rahman, 1967 ; Andersen, 1967).

Few British surgeons have much practical experience of the management of this condition, as major British hospitals admit an average of only one case a year (Bolt, 1956). Apart from a previous report from Uganda (Hall-Craggs, 1960) no review in the British literature has been based on more than 40 cases. In this paper the results of treatment in 425 cases at one hospital are presented, including 140 cases seen by me at some stage of treatment.

\section{Treatment of Sigmoid Volvulus at Mulago Hospital, Kampala}

Most reported series of sigmoid volvulus either present the results of one type of management or involve small numbers treated in a variety of ways. Comparison between two series at different centres involves comparing surgeons and hospitals as well as techniques. In Mulago Hospital, Kampala, Uganda, during the period 1949-65 a total of 425 cases of sigmoid volvulus were treated by more than 30 surgeons of varying seniority and experience, and every type of treatment was carried out by both senior and junior staff. There are therefore grounds for submitting that the varying results achieved are attributable to the different techniques rather than to the different abilities of the clinicians concerned.

It should be emphasized that all the cases reviewed occurred in patients with no known neurological or psychological abnormality. Cases of volvulus in patients from mental institutions or in children with Hirschsprung's disease have been excluded. In reviewing sigmoid volvulus some authors have included cases of a disorder described as "compound volvulus" or "double volvulus" (Hall-Craggs, 1960 ; Easmon and Lahiri, 1963). The prognosis of this condition is very different from that of primary sigmoid volvulus, and the clinical features and treatment have been presented separately in a previous publication (Shepherd, 1967).

\section{Spontaneous Remission}

In nine cases of this series spontaneous relief occurred while awaiting operation and no further treatment was given. The diagnosis was established either by radiology or by laparotomy in another attack. In two personal cases the positioning of a patient in the knee-elbow position preparatory to sigmoidoscopy was instantly followed by the escape of an enormous quantity of flatus.

Two other patients classified as having spontaneous relief (Table I) refused operation and discharged themselves, to return

- Based on material included in a thesis for the degree of M.D. † Department of Surgery, Makerere University College, Kampala, Uganda. 